\title{
Applications and Experience with PCR-Based Assays to Predict Blood Group Antigens
}

\author{
Marion E. Reid \\ New York Blood Center, New York, NY, USA
}

\section{Key Words}

Antibody identification - Blood group antigens . Molecular methods - DNA testing - Blood groups . Identification of blood groups

\section{Summary}

DNA-based tests are increasingly being used to predict a blood group phenotype. This is possible because genes encoding 29 of the 30 blood group systems have been cloned and sequenced, and the molecular bases associated with most antigens have been determined. Red blood cells (RBCs) carrying a particular antigen, if introduced into the circulation of an individual who lacks that antigen, can elicit an immune response. It is the antibody from such an immune response that causes problems in clinical practice and the reason why antigen-negative blood is required for safe transfusion. The classical method of testing for blood group antigens and antibodies is hemagglutination; however, it has certain limitations, some of which can be overcome by testing DNA. Such testing allows conservation of antibodies for confirmation by hemagglutination of predicted antigen negativity. High-throughput platforms provide a means to test relatively large numbers of donors, thereby opening the door to change the way antigen-negative blood is provided to patients. This article discusses how molecular approaches can be applied in transfusion medicine, and summarizes experiences of using laboratory developed tests and DNA arrays at the New York Blood Center.

\section{Schlüsselwörter \\ Antikörperidentifizierung · Blutgruppenantigene · Molekulare Verfahren · DNA-Testung · Blutgruppen . Identifizierung von Blutgruppen}

\section{Zusammenfassung}

DNA-basierte Tests werden zunehmend zur Bestimmung des Blutgruppenphänotyps eingesetzt. Das ist möglich, weil die Gene, die 29 der 30 Blutgruppensysteme kodieren geklont und sequenziert sind und die molekularen Grundlagen der meisten Antigene mittlerweile bestimmt sind. Erythrozyten, die ein bestimmtes Antigen tragen, können, wenn sie in den Blutkreislauf einer Person gelangen, die über dieses Antigen nicht verfügt, eine Immunantwort auslösen. Die Antikörper von solchen Immunreaktionen sind es, die in der klinischen Praxis für Probleme sorgen. Sie sind der Grund, warum für eine sichere Transfusion antigennegatives Blut benötigt wird. Die klassische Methode zur Bestimmung von Blutgruppenantigenen und -antikörpern ist die Hämaggglutination, die allerdings bestimmte Beschränkungen aufweist, die sich durch das Testen der DNA überwinden lassen. Diese Testung erlaubt die Konservierung von Antikörpern zur Bestimmung einer prognostizierten Antigennegativität durch Hämagglutination. Plattformen mit hohem Durchfluss ermöglichen die Testung von relativ vielen Spendern und öffnen so die Tür zu einem neuen Verfahren, wie Patienten mit antigennegativem Blut versorgt werden können. In diesem Artikel wird beschrieben, wie molekulare Ansätze in der Transfusionsmedizin eingesetzt werden können. Darüber hinaus werden die Erfahrungen beschrieben, die wir in New York Blood Center mit solchen im Labor entwickelten Tests und DNA-Arrays gemacht haben.

\section{KARGER}

Fax +497614520714

Information@Karger.de

www.karger.com (c) 2009 S. Karger GmbH, Freiburg 


\section{Introduction}

In the first half of the 20th century, when the knowledge of blood groups was restricted to A, B,O; M,N; P1; and D antigens, phenotyping by hemagglutination was used to predict a genotype. Today, testing of DNA is increasingly being used to predict a blood group phenotype. This is possible because most antigens have been grouped into one of the 30 recognized blood group systems [1-3], and the gene (or a small gene family for MNS, $\mathrm{Rh}, \mathrm{Ch} / \mathrm{Rg}$ systems) encoding each of the blood group systems (the gene encoding P1 remains to be confirmed and published) has been cloned and sequenced [4], and the molecular bases associated with the vast majority of blood group antigens have been determined [5]. Blood groups are inherited, polymorphic (at least for the most part), structural characteristics located on proteins, glycoproteins, or glycolipids on the outside surface of the red blood cell (RBC) membrane. RBCs carrying a particular antigen can, if introduced into the circulation of an individual who lacks that antigen, elicit an immune response. It is the antibody from such an immune response that causes problems in clinical practice, such as patient/donor blood transfusion incompatibility, maternal-fetal incompatibility and autoimmune hemolytic anemia, and the reason why antigen-negative blood is required for safe transfusion in these patients.

The classical method of testing for blood group antigens and antibodies is hemagglutination. This technique has served the transfusion community well for decades, it is simple, requires little equipment, and when done correctly has a specificity and sensitivity that is appropriate for the clinical care of the vast majority of patients requiring blood transfusion. However, hemagglutination, which is a subjective test, has certain limitations:

- It does not reliably predict a fetus at risk of hemolytic disease of the fetus/newborn (HDFN).

- It is difficult to type RBCs from a recently transfused patient and RBCs that are coated with $\mathrm{IgG}$.

- It does not precisely indicate RHD zygosity in D-positive people.

- A relatively small number of donors can be typed for a relatively small number of antigens, thereby limiting antigennegative inventories.

- It requires the availability of specific reliable antisera.

- It is labor-intensive not only in the testing but also in the manual data entry.

- Source material is diminishing.

- The cost of commercially available licensed reagents is escalating.

- Unlicensed reagents are characterized (often partially) by the user.

- Some antibodies are limited in volume, weakly reactive, or not available.

The knowledge of the molecular bases associated with many blood group antigens and phenotypes enables us to consider prediction of the presence or absence of blood group antigens, thereby overcoming some of these longstanding limitations. High-throughput platforms provide a means to test relatively large numbers of donors, thereby opening the door to change the way antigen-negative blood is provided to patients. For patients who require chronic transfusions, it may be possible to provide antigen-negative blood based on matching through DNA testing. Screening donor samples by DNA-based tests allows us to conserve precious antibodies for confirmation by hemagglutination of predicted antigen negativity. The purpose of this article is to discuss how molecular approaches can be applied in transfusion medicine, especially in those areas where hemagglutination is of limited value, and to summarize the experience to date of using DNA-based assays at the New York Blood Center.

\section{Blood Groups and DNA Analysis}

The presence or absence of a blood group traditionally has been determined by phenotyping using serologic methods. The genes encoding 29 of the 30 blood group systems (only the $\mathrm{P}$ system remains to be confirmed) have been cloned and sequenced [2, 4], and the molecular bases of many blood group antigens and phenotypes have been determined [5, 6]. Numerous molecular events generate blood group antigens and phenotypes; however, as most antigens result from a single nucleotide change, simple DNA-based assays can be used to predict the presence or absence of a blood group antigen. Table 1 summarizes the value, reagents, and limitations of hemagglutination and polymerase chain reaction (PCR)-based testing for the prediction of blood groups. The decision as whether to use hemagglutination or DNA methodologies is dependent on various things, such as availability of reagents and the complexity of the molecular basis of an antigen.

Analysis of DNA involves amplification of the target sequence of nucleotides followed by analysis by laboratorydeveloped tests (LDTs), such as PCR-restriction fragment length polymorphism (RFLP), allele-specific PCR, real-time PCR, sequencing, or by DNA arrays. LTDs typically are labor-intensive, and each assay is performed separately on each sample. In contrast, DNA arrays test for multiple markers on one sample simultaneously and, thus, have the potential for high-throughput, to increase antigen-negative inventories, and make it possible to contemplate precisely matching the antigen-negative status of a donor to that of a patient destined to receive multiple transfusions.

\section{Prediction of Blood Groups and Their Clinical Applications}

In the author's laboratory, we have over a decade of experience using LDTs for testing patients and donors to predict their 
Table 1. Features of hemagglutination and PCR-based assays for blood groups antigens

\section{Hemagglutination}

Value

- Is the 'Gold Standard' method to detect the presence or absence of blood group antigens on RBCs

- It is simple and quick to perform, requires little in the way of equipment, and, when done correctly, has a specificity and sensitivity that is appropriate for the vast majority of transfusions

- For decades, direct (over a century) and indirect (over 60 years) hemagglutination tests have served the transfusion community well

- Detects mixed populations of RBCs

Reagents

- Specialized and obtained from immunized patients/donors (polyclonal and monoclonal antibodies), or from immunized mice (monoclonal antibodies)

- Source material is diminishing

- Cost of commercial licensed reagents is escalating

- Many antibodies are not commercially available and are characterized (often only partially) by the user

- Some antibodies are limited in volume, weakly reactive, or not available

Limitations

- Indirect indication of a fetus at risk of hemolytic disease of the fetus/newborn

- Restricted ability to determine zygosity

- Difficult to phenotype a recently transfused patient

- Difficult to phenotype RBCs coated with IgG

- Can be difficult to distinguish an alloantibody from an autoantibody in antigen positive people

- Labor-intensive testing so a relatively small number of donors can be typed for a relatively small number of antigens, which has limited the size of antigen-negative inventories

- Labor-intensive manual data entry

- Is a subjective test

\section{PCR-based assays}

Value

- Can be automated

- High throughput

- Interpretation by computer and entry into a patient/donor data base

- Computer matching of donor RBC components to patient type

\section{Reagents}

- Does not require special reagents

- Can be purchased

- Probes and primers need to be specific for the target

Limitations

- Antigen type is a prediction, and it is recommended that the prediction be confirmed by hemagglutination

- Takes hours

- DNA and hemagglutination test results may not agree

- PCR errors introduced by Taq in PCR

- Preferred amplification of one allele in PCR

- Silenced alleles in null phenotypes due to, e.g., a premature stop codon, alternative splicing, change in a nucleotide in a transcription factor, nucleotide(s) insertion or deletion, gene rearrangements, absence of an interacting protein

Non-synonymous changes that result in an unstable form of the protein

- Change in restriction enzyme cutting site

- Change in primer or probe binding site

Presence of hybrid alleles

- Preferential amplification of one allele in a heterozygote

- Three or more alleles (e.g. $\mathrm{Kp}^{\mathrm{a}}, \mathrm{Kp}^{\mathrm{b}}, \mathrm{Kp}^{\mathrm{c}}$ )

- After recent transfusion

- Following allogeneic stem cell transplant

- In a natural chimera

- If fetal sample is contaminated with maternal blood

- In a surrogate mother or a woman who was artificially inseminated

- DNA results from somatic cells and from WBCs may not agree

- In patients with an allogeneic stem cell transplant

- In a natural chimera

- More than one genotype can give rise to the same phenotype; especially with the null phenotypes

- Likely that not all molecular events have been identified 
Table 2. Applications of PCR-based assays to predict a blood group antigen

\section{Antigen typing a patient}

To identify a fetus not at risk for HDFN

When antibody is weak or not available, e.g., anti-Do ${ }^{\mathrm{a}},-\mathrm{Do}^{\mathrm{b}},-\mathrm{Js} \mathrm{s}^{\mathrm{a}},-\mathrm{V} / \mathrm{VS}$

Who has been recently transfused

- Aid in antibody identification

- Select RBCs for adsorption

To distinguish an alloantibody from an autoantibody (e.g. anti-e, anti-Kp ${ }^{\mathrm{b}}$ )

To help identify alloantibody when patient's RBCs type antigen-positive (e.g. anti-D in a D-positive, anti-e in a e-positive)

Whose RBCs are coated with immunoglobulin (+DAT)

- When direct agglutinating antibodies and murine Mabs are not available

- When antisera are weakly reactive, e.g. anti-Do ${ }^{\mathrm{a}}$, anti-Do ${ }^{\mathrm{b}}$

- When the antigen is sensitive to the IgG removal treatment, e.g. antigens in the Kell blood group system are denatured by the EDTA-glycine-acid elution method

Who has received an allogeneic stem cell transplant

- If antibody problem arises, test stored DNA samples from a patient and the donor(s)

To detect weakly expressed antigens (e.g. $\mathrm{Fy}^{\mathrm{b}}$ with the $\mathrm{Fy}^{\mathrm{x}}$ phenotype); where the patient is unlikely to make antibodies to transfused antigen-positive RBCs

To identify molecular basis of unusual serological results, especially $\mathrm{Rh}$ variants

To determine zygosity

- For donors on antibody detection/identification reagent RBCs, namely D, S, Fy and $\mathrm{Fy}^{\mathrm{b}}$

- When a prospective mother has anti-D, this can be valuable to predict if her partner is homozygous or heterozygous for $R H D$

Antigen typing for donors

To screen for antigen-negative donors

When antibody is weak or not available, e.g. anti-Do ${ }^{\mathrm{a}},-\mathrm{Do}^{\mathrm{b}} ;-\mathrm{Js}^{\mathrm{a}},-\mathrm{Js}$; $-\mathrm{V} / \mathrm{VS}$

Mass screening to increase antigen-negative inventory

To find donors whose RBCs lack a high-prevalence antigen

To resolve blood group A, B, D, C, and e discrepancies

To detect genes that encode weak antigens

To type donors for reagent RBCs for antibody screening cells and antibody identification panels
Table 3. Uses of PCR-based assays for the prediction of blood group antigens

\section{Best suited for predicting}

'Minor' blood group antigens

Rh variants

$\mathrm{ABO}$ variants

Certain null phenotypes

New blood groups

Not ideal for

$\mathrm{ABO}$ routine

$\mathrm{Rh}(\mathrm{D})$ routine

Many null phenotypes

\section{Considerations}

Test once and confirm subsequent samples with a simple assay for a unique sequence of DNA

Test as needed versus all blood donors and transfusion candidates

Test all newborns or all people

How many markers should, or can, be tested

RBC phenotype, and find the information obtained valuable in providing optimal patient care. We have found this approach particularly useful i) to aid in antibody identification (recently transfused patients and those whose RBCs are positive in the direct antiglobulin test (DAT)) to not only predict which al- loantibodies can be made by the patient but also to select RBCs for absorption (especially in patients with autoimmune hemolytic anemia (AIHA) and antibodies to a high-prevalence antigen), ii) to differentiate alloantibodies from autoantibodies, iii) to detect a fetus not at risk for HDFN, iv) to screen for antigen-negative donors, v) to test donor samples for our inhouse antibody identification panel, and vi) to investigate new antibodies and antigens. We have recently included testing by DNA arrays; namely, the SNaPshot ${ }^{\mathrm{TM}}$ methodology (ABI, Foster City, CA, USA) [7] and the HEA Beadchip ${ }^{\mathrm{TM}}$ (BioArray Solutions, Warren, NJ, USA). Table 2 lists some applications of DNA typing for the prediction of blood groups; some are discussed in more detail below.

When feasible, the appropriate assay to detect a nucleotide change that silences a gene should be part of the DNA-based testing; e.g., GATA box and $F Y^{*} 265$ (for $F y^{\mathrm{x}}$ ) analyses with $F Y A / F Y B$ typing [8], presence of $R H D$ pseudogene with $R H D$ typing [9], and exon 5/intron 5 analysis with $G Y P B^{*} S$ typing [10]. While a nucleotide change $(\mathrm{t}>\mathrm{c})$ in the GATA-1 binding motif is the basis of the Fy(a-b-) phenotype in blacks, the $\mathrm{Fy}(\mathrm{a}-\mathrm{b}-)$ phenotype in whites is very rare and associated with silencing of $F Y^{*} A$ or $F Y^{*} B$ by at least 4 different molecular bases [8]. Several changes that silence the $\mathrm{JK}^{*} \mathrm{~A}$ and $\mathrm{JK}^{*} \mathrm{~B}$ alleles have been identified [11]. This knowledge shows that 
variants exist and begs the question as to how much testing is practical or feasible. The limited DNA testing used for clinical utility will not allow accurate interpretation of all alleles; thus, in this scenario, the 'genotype' may not be the phenotype, and confirmation of predicted antigen negativity by hemagglutination is recommended. These and other considerations are presented in an International Forum [12] and in a review article by Hillyer et al. [13]. Table 3 lists the recommended use for DNA testing for the prediction of blood groups.

\section{DNA Typing to Identify a Fetus at Risk for Anemia of the Neonate}

Hemagglutination, including antibody titers, gives only an indirect indication of HDFN risk and severity. Antigen prediction by PCR-based assays can be of value in the prenatal setting in identifying the fetus who is not at risk of HDFN (i.e. predicted to be antigen-negative) so that the mother need not be aggressively monitored. Testing DNA should be considered when a mother's serum contains an $\operatorname{IgG}$ alloantibody that has been associated with HDFN and the father's antigen status for the corresponding antigen is heterozygous, indeterminable, or he is not available for testing. Sources of fetal DNA include amniocytes and maternal plasma.

For prenatal diagnosis of a fetus at risk of HDFN, the strategy should be to detect a gene even if the product is not expressed on the RBC membrane rather than fail to detect a gene whose product is expressed because this could result in inadequate monitoring throughout pregnancy. To reduce the likelihood of error in interpretation, it is helpful to test DNA from the parents. If this is not possible, and because the prevalence of genes can vary substantially in different populations, it can be helpful to know the ethnicity of the parents. A potential pitfall is the possibility of contamination of the fetal sample with maternal DNA.

The RHD type is a prime target because anti-D is notoriously clinically significant in terms of HDFN [reviewed in 14], and even today, a high proportion of HDFN cases are caused by anti-D. PCR analyses for the prediction of fetal D phenotype are based on predicting the presence or absence of specific portions of $R H D$. In Europeans, the molecular basis of the D-negative phenotype is usually associated with deletion of the entire $R H D$, but several other molecular bases have been described [15]. About a third of D-negative Japanese have an intact but inactive RHD [16], and as many as $10 \%$ of Japanese donors who had RBCs that were non-reactive with anti-D have the $\mathrm{D}_{\mathrm{el}}$ phenotype [17]. About a quarter of D-negative African Americans have an $R H D$ pseudogene (RHD $)$, which does not encode the $\mathrm{D}$ antigen [18], and many others have a hybrid $R H D$-CE-D gene (e.g. the $\mathrm{r}$ 's phenotype). To predict the $\mathrm{RhD}$ antigen type by DNA analysis requires probing for multiple nucleotide changes [9]. The choice of assays depends upon the ethnicity and degree of comfort desired [19].
Establishing the fetal KEL genotype is also of great clinical value in determining whether a fetus is at risk for severe anemia, because the strength of the mother's anti-K antibody does not correlate with the severity of the infant's anemia [20]. The same is true for anti-Ge3 [21].

When performing DNA analysis in the prenatal setting, it is also important to always determine the RHD status of the fetus, in addition to the test being ordered. In so doing, if the fetus has a normal $R H D$, there is no need to provide Rhnegative blood for intrauterine transfusions. For example, if a mother has anti-c and fetal DNA is being typed for $R H C E^{*} c$, in the absence of a predicted D type of the fetus, r'r' RBCs would be ordered for an intrauterine transfusion, whereas if the fetus is predicted to be $D$-positive then $R_{1} R_{1}$ RBCs are appropriate.

\section{DNA Typing to Predict Blood Group Antigens in Transfusion Candidates}

Knowledge of the RBC phenotype of a patient is an invaluable part of the antibody identification process. When a patient receives transfusions, the presence of donor RBCs in the patient's peripheral blood makes RBC phenotyping by hemagglutination complex, time-consuming, and possibly inaccurate. Indeed, the 'best guess' of a patient's antigen type based on the strength of hemagglutination, the number of RBC components transfused, the length of time since transfusion, the estimated blood volume of the patient, and the prevalence of the antigen in question is more often inaccurate than accurate [22]. To overcome this problem, PCR-based assays using DNA isolated from WBCs, buccal smear, or urine sediment can be used to predict the antigen type of patients. Any donor WBCs in a transfused patient's circulation do not interfere with PCR-based assays, at least in the way we perform them [23-26].

For over a decade, we have used LDTs to predict the RBC phenotype of a high proportion of patient samples submitted for antibody identification investigation. Our assays test for the standard clinically relevant antigens as well as for weak antigen expression, e.g. $\mathrm{Fy}^{\mathrm{b}}$ in the $\mathrm{Fy}^{\mathrm{x}}$ phenotype where a patient is unlikely to make anti-Fy ${ }^{b}$ if transfused with $\mathrm{Fy}(\mathrm{b}+) \mathrm{RBC}$ components. In addition, we use LTDs to aid in identification of more uncommon antibodies, e.g. to indicate specific Knops antigen negativity from a low copy number of CR1 (CD35) and to identify antibodies to Cromer blood group antigens. If the initial findings of an investigation indicate an antibody to a Cromer system antigen, serological testing is halted, and DNA analyses are performed on the sample. Any findings are then confirmed serologically, providing suitable serum and cell samples are available. The scarce quantities of rare RBCs and sera for certain blood groups are conserved so as to be available for other investigations.

DNA-based antigen typing of patients with AIHA, whose RBCs are coated with immunoglobulin (positive in the DAT), 
is valuable when i) direct agglutinating antibodies, or murine monoclonal antibodies, are not available; ii) antisera are weakly reactive; iii) antigen is sensitive to the $\mathrm{IgG}$ removal treatment; and iv) diagnostic antibodies require the indirect antiglobulin test and IgG removal techniques are not effective at removing cell-bound immunoglobulin. DNA-based assays are also useful as a tool to distinguish alloantibodies from autoantibodies and to identify the molecular basis of unusual serological results.

When recommendations for clinical practice are based on molecular analyses, it is important to remember that, in rare situations, a genotype determination will not correlate with antigen expression on the RBC [27]. If a patient has a grossly normal gene that is not expressed, he/she could produce an antibody if transfused with antigen-positive blood. As described above, when feasible, the appropriate assay to detect a change that silences a gene should be included as part of the DNA-based testing. Also, it is important to obtain an accurate medical history for the patient because with certain medical treatments, such as stem cell transplantation, results of DNA typing may differ from results obtained by hemagglutination.

\section{DNA Testing for Antigen-Negative Blood Donors}

PCR-based assays are particularly valuable to predict the antigen profile of a blood donor when the antibody is weak or not readily available, e.g. anti-Do ${ }^{\mathrm{a}}$, anti-Do ${ }^{\mathrm{b}}$, anti-Hy, anti-Jo ${ }^{\mathrm{a}}$, anti-Js ${ }^{\mathrm{a}}$, anti-Js $\mathrm{s}^{\mathrm{b}}$; anti- $\mathrm{C}^{\mathrm{W}}$, anti-V, and anti-VS. Testing for these antigens by DNA analyses is accomplished without the need for special reagents (antibodies) and is an example of where PCR-based assays surpass hemagglutination for antigen typing. Using LDTs, only a limited number of donors can be tested; however, DNA arrays, with their high-throughput capability, are particularly suited for mass screening donors. This technology provides a tool to enable us not only to increase the antigen-negative inventory of combinations of the minor antigens and of high-prevalence antigens, but also to consider the possibility of providing donor RBC products that are DNA-matched to the patient's type. DNA-based assays also can be useful to detect genes that are predicted to encode weakly expressed antigens and thereby prevent immunization or possible transfusion reactions.

With donor typing, the presence of a grossly normal gene whose product is not expressed on the RBC surface would lead to the donor being falsely typed as antigen-positive, and although this would mean loss of an antigen-negative donor, it would not jeopardize the safety of blood transfusion. As automated procedures attain higher and faster throughput at lower cost, typing of blood donors by PCR-based assays is likely to become more widespread. Screening for rare donors by analysis of DNA is valuable for typing for 'minor' antigens and $\mathrm{Rh}$ variants. Those antigens that are predicted to be negative should be confirmed by hemagglutination. In this man- ner, precious antibodies are conserved for the confirmation of DNA typing interpretations.

$\mathrm{RBC}$ typing for $\mathrm{Do}^{\mathrm{a}}, \mathrm{Do}^{\mathrm{b}}, \mathrm{Hy}$ and $\mathrm{Jo}^{\mathrm{a}}$ antigens is notoriously difficult because the corresponding antibodies, although potentially of clinical significance, are often weakly reactive, available only in small volume, and present in sera containing other alloantibodies [28]. At the New York Blood Center, for over a decade we have used PCR-RFLP LDTs (RFLP = restriction fragment length polymorphism) to type donors selected to lack certain combinations of antigens (e.g. C-, E-, $\mathrm{K}-, \mathrm{Fy}(\mathrm{a}-), \mathrm{Jk}(\mathrm{b}-))$ for $D O * A$ and $D O * B$ for patients who have antibodies to multiple antigens in addition to anti-Do ${ }^{\mathrm{a}}$ or anti-Do ${ }^{\mathrm{b}}$. We also test donors whose $\mathrm{RBCs}$ react weakly or do not react with human polyclonal anti-Gy for $D O * H Y$ and $D O * J O$, which has provided us with a larger inventory of valuable $\mathrm{Hy}-$ and Jo(a-) donors. Due to the dearth of appropriate antiserum, testing for polymorphisms in the Dombrock system by DNA analysis surpasses hemagglutination for antigen typing.

\section{DNA Typing for Low-Prevalence Antigens}

Patients in the area serviced by New York Blood Center, often need RBC components that are Js(a-), V-, VS-, Go(a-), or DAK-. Providing antigen-negative $\mathrm{RBC}$ products for these patients is difficult because patients typically have several other antibodies, e.g. anti-C, anti-E, anti-K, anti-Fy ${ }^{\mathrm{a}}$, and anti-Jk ${ }^{\mathrm{b}}$, in their serum/plasma. While these immunogenic antigens are of low prevalence in Caucasian donors, they are present on up to $20 \%$ of RBCs from African American donors. As a natural consequence of transfusing $\mathrm{Rh}$ and $\mathrm{K}$ ethnically matched $\mathrm{RBC}$ components to patients, as in the Stroke Prevention (STOP) trials $[29,30]$, they have made antibodies to these 'low-prevalence' antigens. These antigens are not on antibody screening RBCs, the corresponding antibodies are not available to screen for suitable donors, and the cross-match is not always reliable for their detection. PCR-based assays provide a tool to mass screen donors, thereby increasing the antigen-negative inventory and improving patient care.

As an illustration, we had a patient whose serum contained anti-U, anti-C, anti-E, anti-K, plus anti-VS, and anti-Js ${ }^{\mathrm{a}}$. Of 95 eligible U- C- E- K- donors in our inventory, we had four who had been typed as VS-, Js(a-), 27 who were VS+ and/ or Js(a+), and 64 who had not been typed for either antigen. Anti-VS and anti-Js ${ }^{\mathrm{a}}$ were not available in sufficient volume for typing. PCR-based methods, which do not require special reagents, can be used to screen for needed antigen-negative donors. LDTs are labor-intensive but the availability of DNA arrays makes this approach feasible.

\section{DNA Typing for High-Prevalence Antigens}

As anti-Lu ${ }^{\mathrm{b}}$, anti-Yt $\mathrm{t}^{\mathrm{a}}$, anti-Sc1, anti-LW, and anti-Co ${ }^{\mathrm{a}}$ are inconsistently available, testing DNA is a desirable alternative. The readily availability of anti-k, anti- $\mathrm{Kp}^{\mathrm{b}}$, anti-Js ${ }^{\mathrm{b}}$, and anti-Fy3 often makes hemagglutination the method of choice for these 
antigens. On the other hand, as probes for various nucleotide changes can be added to a microchip at little incremental cost, all of the above antigens could be assayed simultaneously. Detection of Vel-, Lan-, $\operatorname{At}(\mathrm{a}-)$, or $\operatorname{Jr}(\mathrm{a}-)$ donors is restricted to hemagglutination because the molecular bases of these antigen are not yet known. Detection of null phenotypes such as $\mathrm{Rh}_{\text {null }}$, $\mathrm{K}_{0}, \mathrm{~Gy}(\mathrm{a}-)$, Ge-, or McLeod is complex due to multiple molecular bases associated with each of these phenotypes [5].

\section{DNA Testing for the Prediction of $A B O$ and RHD Alleles}

In the author's opinion, DNA analysis is not the method of choice for routine $\mathrm{ABO}$ and $\mathrm{D}$ determination of donor blood. The reasons include the following: the naturally occurring antiA and/or anti-B in the plasma of most people who lack the corresponding antigens provides a built-in check when performing ABO typing by hemagglutination; potent, well-standardized monoclonal reagents are available for $\mathrm{ABO}$ and D typing; hemagglutination is relatively simple and rapid; and systems are in place to test and record, relatively efficiently, the ABO and $\mathrm{D}$ type of a donor. In both $\mathrm{ABO}$ and $\mathrm{Rh}$ systems, there are few antigens and many alleles. In the $\mathrm{ABO}$ system there are four primary phenotypes ( $\mathrm{A}, \mathrm{B}, \mathrm{AB}, \mathrm{O})$, but over 160 alleles. In the $\mathrm{Rh}$ system, $\mathrm{D}$ is one antigen but there are over 150 RHD alleles known. In both scenarios, it is highly likely that more alleles exist and await discovery. Furthermore, RBCs with a weak expression of the $\mathrm{D}$ antigen are almost always $\mathrm{C}+$ or $\mathrm{E}+$. Thus, the fear of transfusing apparently D- RBCs that actually express some serologically non-detectable $\mathrm{D}$ antigen can be overcome by transfusing D- C- E- RBCs (which are usually truly D-) rather than by using PCR-based assays to detect the multitude of alleles involved in the weak D phenotypes. For routine $\mathrm{ABO}$ and $\mathrm{D}$ determination, DNA testing is more time-consuming, more expensive, prone to misinterpretation, and thus not an improvement over hemagglutination.

DNA analysis for $\mathrm{ABO}$ and $\mathrm{Rh}$ types can be of value in the resolution of $\mathrm{ABO}$ and $\mathrm{D}$ discrepancies in order to show that a discrepancy is due to a genetic variant (without having to perform laborious family studies), and not to technologist error or reagent failure and, thus, not an regulatory agency reportable error. ABO genotyping also can be useful for distinguishing an acquired phenotype from an inherited one. Many $\mathrm{Rh}$ phenotypes cannot easily be defined by hemagglutination, either because suitable panels of monoclonal antibodies are not readily available or the antibodies are not available in needed strength or volume. PCR-based assays may be useful to define some $\mathrm{Rh}$ variants and to precisely match $\mathrm{D}$ and e antigen status of a donor to a recipient, especially in the case of patients with sickle cell disease (SCD). Of particular note are $\mathrm{hr}^{\mathrm{S}}$ and $\mathrm{hr}^{\mathrm{B}}$ antigens, the absence of which is known to be encoded by several distinct alleles [31]. Although several assays are required, DNA-based assays can be used to differentiate some alleles encoding $\mathrm{hr}^{\mathrm{S}}-$ or $\mathrm{hr}^{\mathrm{B}}-$ phenotypes.

\section{DNA Testing Donors for Antibody Identification Panels}

PCR-based assays can be used to predict the antigen type of donor RBCs for transfusion and for antibody identification reagent panels [32]. Again, this is particularly useful when antibodies are not available or are weakly reactive. Examples are $\mathrm{Do}^{\mathrm{a}} / \mathrm{Do}^{\mathrm{b}}, \mathrm{Js}^{\mathrm{a}}$, and $\mathrm{V} / \mathrm{VS}$ where DNA-based assays are used to type donors in order to overcome the dearth of reliable typing reagents. PCR-based assays are also useful to confirm whether an antigen is truly present in a double dose, especially $\mathrm{S}, \mathrm{D}$, $\mathrm{Fy}^{\mathrm{a}}, \mathrm{Fy}^{\mathrm{b}}, \mathrm{Jk}^{\mathrm{a}}$, and $\mathrm{Jk}^{\mathrm{b}}$. We have also found LDTs valuable to differentiate specific Knops antigen negativity from a low copy number of CR1 (CD35) of donors used on our in-house antibody identification panel.

\section{DNA Arrays}

Common features of the various DNA arrays that are available to predict a blood group phenotype include the presence of multiple probes for selected nucleotide polymorphisms or short insertions or deletions on a solid surface (chip, wafer, bead), single tube multiplexed PCR amplification, detection of reactions on the array, and automated image acquisition and interpretation of multiple data points for the same polymorphism. These high-throughput technologies have the potential to dramatically increase inventories of antigen-negative blood by allowing cost-effective mass screening of donor samples. DNA arrays test for multiple markers on one sample simultaneously. As the incremental cost for adding a marker to a basic DNA array platform is negligible, a large number of samples can be tested for a large number of nucleotide changes, at least in theory, at a feasible cost. The actual cost of the approach will depend on how much the manufacturers charge for kits they develop. Blood group prediction by SNaPshot, which allows the simultaneous analysis of up to 10 single nucleotide changes in any combination of the users choice, has a turnaround time of $24 \mathrm{~h}$ with average reagent cost around USD 2.00 per SNP detected [7].

Another advantage of this technology is that results can be analyzed, interpreted, and documented by computer. Furthermore, there is the potential to directly download interpretations to a donor/patient database. Collectively, this will reduce data entry errors inherent in manual systems. An added cost of doing DNA testing could be the expense of investigating any discrepancies.

There are an increasing number of DNA array platforms available from commercial sources (e.g. BioArray Solutions (BAS beadchip), BioTrove (OpenArray), Progenika (BloodGen bloodchip), GTI (Red Cell EZ Type)). Desirable characteristics for a DNA array include that it uses robust chemistry, allows easy addition of probes to detect multiple nucleotide changes, allows for automation and minimal hands-on time, and is reliable, consistent, flexible, specific, sensitive, and of feasible cost. 


\section{Experience with DNA Array}

In 2005, with BioArray Solutions, we published results of a pilot study in which we demonstrated feasibility of using a DNA array platform to predict minor blood group antigens. The platform was verified and validated with at least two samples that were known to be heterozygous, or homozygous for each nucleotide change (i.e. at least six samples for each pair of alleles), and 14 fully typed in-house panel donors. The samples were tested for $F Y^{*} A / B ; F Y-G A T A ; D I^{*} A / B ; S C^{*} 1 / 2 ; D O^{*} A$ / $B$; $C O^{*} A / B$; and $L W^{*} A / B$. Partially phenotyped New York donor samples $(\mathrm{n}=400)$ as well as cohorts from Chinese, Israeli, and Thai donors were tested. There was good correlation of the results, and two new Dombrock alleles $(D O * B-S H$ and $D O * B-H A$ ) were found. This showed that the three nucleotide changes previously associated with $\mathrm{Do}^{\mathrm{a}}$ or $\mathrm{Do}^{\mathrm{b}}$ were not invariant. Two plates (192 DNA samples) could be tested per 8-hour shift [33].

In a second study, we tested an extended panel (prototype HEA BeadChip) prepared by BioArray Solutions. The original 'proof of concept' panel was expanded to include nucleotide changes associated with $G Y P A * M / N ; G Y P B * S / s$, $G Y P B^{*} 230, G Y P B^{*} I 5, L U^{*} A / B ; K E L 1 / 2, F Y-265, J K^{*} A / B$, $D O * 323(\mathrm{Hy}), D O * 350\left(\mathrm{JO}^{a}\right)$, and HBS. We analyzed 2,355 donor samples (Asian $\mathrm{n}=51$, Blacks $\mathrm{n}=695$, Caucasian $\mathrm{n}=$ 1,244 , Hispanic $n=119$, and others $n=246$ ) for 24 antigens in 10 blood group systems. There was concordance with 4,510 antigen-negative typings (99.5\%), and there were 19,457 new antigen-negative predictions. The discordances were attributable to clerical errors found on original data entry, and for $\mathrm{S}$ typings as a result of silencing changes, which are included in the HEA 1.1 BeadChip [34].

The HEA 1.1 BeadChip was first validated by the New York Blood Center, extracting DNA from 396 donor samples, with BioArray Solutions performing the assay. 28 antigens were analyzed. Of the 9,578 tests, $62 \%(n=5,952)$ were predicted to be antigen-positive, and $38 \%(n=3,626)$ were predicted to be antigen-negative. $67 \%(n=2,428)$ of the negative results were new results (i.e. there was no previous serology testing). Of particular note, the testing revealed six new SC:-1 donors, as well as three e- and many c-, and s- donors that have been confirmed by hemagglutination. There were eight conflicting results, which were likely due to typographical errors. A second validation of the HEA 1.1 BeadChip was subsequently performed with New York Blood Center personnel. The operational qualification consisted of 68 samples with known C/c, E/e, M/N, S/s, K/k, Fy ${ }^{\mathrm{a}} / \mathrm{Fy}^{\mathrm{b}}$, and $\mathrm{Jk}^{\mathrm{a}} / \mathrm{Jk}^{\mathrm{b}} \mathrm{RBC}$ phenotypes. Included were six known samples (DNA from cell lines) and controls tested in replicate. 67 of the 68 samples were found to be concordant with the historic records for all antigens tested. The one sample that did not correlate, had a historical serotype of c-, E-. The HEA 1.1 BeadChip test predicted that the sample would possess $\mathrm{c}$ and $\mathrm{E}$ antigens. Repeat hemagglutination and DNA testing by LDT confirmed both results. This sample is being investigated further, but the apparent discordance is likely attributable to a silenced $R H C E^{*} c E$ allele. For performance qualification, the New York Blood Center tested 960 specimens with unknown phenotypes. Once tested, predicted antigen-negative results were confirmed with serology. There were no discordant results.

\section{Patient Care and Antigen-Negative RBC Component Availability}

The value of access to larger numbers of antigen-negative RBC components is multifaceted. If antigen-negative inventories were sufficient, the following uses of antigen-matched blood could be contemplated:

i) Prevention of morbidity and mortality due to transfusion reactions. Consideration should be given to the cost to screen for antigen-negative donors versus the cost to treat a patient with a transfusion reaction.

ii) To reduce the need to withhold RBC components to alloimmunized patients (especially those with multiple alloantibodies where providing antigen-negative blood has been a challenge). This could ameliorate the clinical risks of withholding blood transfusion.

iii) To prevent immunization and transfusion reactions by matching antigen profiles in chronically transfused patients who are immune responders, especially those with SCD.

iv) To provide $\mathrm{RBC}$ components lacking antigens for which there is no antibody for screening purposes (e.g. V/VS, $\left.\mathrm{Go}^{\mathrm{a}}, \mathrm{DAK}, \mathrm{Js}^{\mathrm{a}}, \mathrm{Do}^{\mathrm{a}}, \mathrm{Do}^{\mathrm{b}}\right)$.

v) To match, based on DNA testing, unusual Rh phenotypes especially in African American $\left(\mathrm{hr}^{\mathrm{B}}-, \mathrm{hr}^{\mathrm{S}}\right.$-, etc.).

vi) To match for $\mathrm{Jk}^{\mathrm{a}}$ and $\mathrm{Jk}^{\mathrm{b}}$ if a patient has been exposed to either antigen and to prevent transfusion reactions and deaths due to anti-Jk ${ }^{\mathrm{a}}$ or anti-Jk $\mathrm{J}^{\mathrm{b}}$. Reports by the Food and Drug Administration (FDA) in the USA and the Serious Hazards of Transfusion (SHOT) study in the UK have revealed that a handful of patients die annually after being transfused with antigen-positive blood [11].

vii) To transfuse a patient with an alloantibody to a high-prevalence antigen with antigen-matched $\mathrm{RBC}$ components, and thereby reduce the need for maintaining a large library of rare reagents.

viii) For patients with AIHA to reduce need for labor-intensive procedures that are required to detect underlying clinically significant antibodies each time the patient requires blood transfusion.

ix) Testing DNA on high throughput platforms would also provide the possibility to transfuse RBC components matched for phenotypes such as Del and $\mathrm{D}_{\text {weak }}$ to conserve true D-negative blood for true D-negative patients.

To maintain an adequate inventory of antigen-negative RBC components, the New York Blood Center currently screens the following donor samples per week. The computer program de- 
scribed above provides us with a means by which to select samples from donors who have not been previously tested for these antigens. By hemagglutination, we screen approximately 600 group $\mathrm{O}$ and group $\mathrm{A}$ donor samples for a total of 11 antigens (C, c, E, e, K, Fy ${ }^{\mathrm{a}}, \mathrm{Fy}^{\mathrm{b}}, \mathrm{Jk}^{\mathrm{a}}, \mathrm{Jk}^{\mathrm{b}}, \mathrm{S}, \mathrm{s}$ ) for 'common' combinations, and more than 200 donor samples for 15 high-prevalence antigens $\left(\mathrm{U}, \mathrm{hr}^{\mathrm{B}}, \mathrm{hr}^{\mathrm{S}}, \mathrm{Rh} 17, \mathrm{k}, \mathrm{Kp}^{\mathrm{b}}, \mathrm{Js}^{\mathrm{b}}, \mathrm{Yt}^{\mathrm{a}}, \mathrm{Gy}^{\mathrm{a}}, \mathrm{Hy}, \mathrm{Jo}^{\mathrm{a}}, \mathrm{Ge}\right.$, PP1P ${ }^{\mathrm{k}}$, Vel, Lan). By PCR-based assays, we screen approximately 10 samples by LDT for V, VS, hr ${ }^{\mathrm{B}}, \mathrm{hr}^{\mathrm{s}}, \mathrm{Do}^{\mathrm{a}}, \mathrm{Do}^{\mathrm{b}}, \mathrm{Hy}$ and $\mathrm{Jo}^{\mathrm{a}}$, and approximately 90 samples by HEA BeadChip. We anticipate reduction or cessation of LDTs as we develop confidence in the DNA array. With this amount of screening, we can supply the majority of requests for antigen-negative RBC components.

The automation of molecular testing generates an abundant amount of data, and careful consideration must be given as to how to manage it. The New York Blood Center has developed a computer program that searches for results by chip name, carrier ID, or date. Any combination of antigen-negative results may be chosen to find components or donors of interest. The program identifies new negative results and provides the location of retention tubes for ease of retrieval for confirming the prediction by hemagglutination. In addition, it gives the user the capability to review and override results to ensure proper use of the information. If a patient is found to have a clinically significant antibody, a test result may be entered into the blood bank system for that patient. As a consequence of the test result, the software prohibits the distribution of an incompatible blood component to the patient. If a blood component is requested for a patient that has not been tested by the blood center, the order entry may include a specific phenotype. If units are selected that do not match the requested phenotype, the order cannot be filled and prompts the user.

\section{Limitations of DNA Analysis}

Testing by DNA analyses has technical, medical, and genetic pitfalls, and is not approved by the FDA $[35,36]$. Medical pitfalls include recent transfusions, stem cell transplantation, and natural chimerism. In these scenarios, results of testing DNA may not agree with hemagglutination results. Stem cell transplantation and natural chimerism also may cause results of testing DNA from somatic cells to differ from results of testing DNA from WBCs. Thus, when embracing DNA testing, it is important to obtain an accurate medical history. There are many genetic events that cause apparent discrepant results between hemagglutination and DNA test results [36]; the genotype is not the phenotype. Confirmation by hemagglutination of predicted antigen negativity is recommended using a reagent antibody if available, and/or by cross-matching using a method optimal for detection of the antibody/antigen in question.
From a practical perspective, not all blood group polymorphisms can be analyzed; for example, if a large number of alleles encode one phenotype (e.g. ABO, Rh, and null phenotypes in many blood group systems), or alleles with a large deletion (e.g. GE:-2.3 and GE:-2-3-4), or a hybrid alleles (e.g. in the $\mathrm{Rh}$ and MNS systems), or when the molecular basis is not yet known (e.g. Vel, Lan, Jra). Additionally, there is a high probability that not all alleles in all ethnic populations are known. Many molecular events result in the genotype and phenotype being apparently discrepant, and more than one genetic event can give rise to the same phenotype. This is especially true for null phenotypes, for example for $\mathrm{Rh}[14,37]$, Kell [38], and Kidd systems [39], and the p phenotype.[40] Detection of null phenotypes, e.g. $\mathrm{Rh}_{\text {null }}, \mathrm{K}_{0}$, McLeod, is complex by DNA analysis because of multiple molecular bases but easy by hemagglutination; for example, to detect D- - test RBCs with anti-Rh17 (or anti-C and anti-c), to detect Fy(a-b-) test RBCs with antiFy3, and to detect Jk(a-b-) test RBCs with anti-Jk3 or test for the resistance of such RBCs to lysis by $2 \mathrm{M}$ urea [41].

As discussed above, the molecular bases associated with a large number of antigens have been reported. However, in many cases the analysis has been restricted to a relatively small number of people with known antigen profiles. This information is being applied to DNA typing with the assumption that such analysis will correlate with RBC antigen typing in all populations. However, we are still in our infancy of understanding gene variations in different ethnic groups and their significance to the expression of blood group antigens. Much larger numbers of people, from a variety of ethnic backgrounds, need to be analyzed in order to establish more firmly the correlation between genotype and the blood group phenotype. Until such data is available, caution should be exercised when recommending clinical practice based on DNA typing for blood group antigens.

\section{DNA Testing, Informed Consent and Regulatory Compliance}

Whether a study is considered exempt, expedited, or requires a full review by the Institutional Review Board (IRB) depends on several factors. Namely: whether the sample is being tested for clinical purposes or research, whether the sample already exists or is collected specifically for the study, whether it is unlinked or linked, and whether there is a risk or not to the human subject. If a sample is tested for patient care, no IRB approval is needed. However, if results are found to be interesting enough to be published as either an abstract or article, informed consent from the patient or donor should be obtained.

Donor consent may or may not be needed. This will depend on the wording of the local laws and the Donor Registration Form with regard to how the testing for blood groups antigens will be performed. There is much concern that testing 
DNA will reveal unwanted information about a donor. However, as the assays are not intended to identify or diagnose a genetic disease, they are not considered to be 'genotyping' but rather are a different procedure to predict an antigen type. According to the FDA, tests performed on DNA for the prediction of blood groups are for investigation use only (LDTs) or research use only (commercial DNA arrays), and results should not be used as the sole means of determining the antigen status for clinical use; i.e., results should be confirmed with a licensed reagent if available. Any reports using DNA tests must contain a disclaimer.

As with all new technologies a training and competency program must be adhered to and the vendor should be included in this endeavor. It is the responsibility of the director of the laboratory, and not of the vendor, to ensure results are accurate. As with any laboratory testing, competency must be repeated in 6 months and then annually. The AABB published standards for molecular testing at the end of 2008 and the Consortium for Blood Group Genes (CBGG) has ISO style guidelines for DNA testing.

\section{Concluding Remarks}

To apply molecular approaches to clinical situations, several areas of knowledge are needed; for example, a knowledge of molecular techniques, of gene structure and processing, of the molecular bases of blood groups, of hemagglutination techniques, of the expression of blood group antigens, of factors that may affect interpretation of genotype (e.g. chimeras), and of regulatory compliance (current good laboratory practice, IRB, FDA) as well as an ability to correlate DNA and serological results to the clinical problems being addressed.
Other considerations include establishing the extent of testing alleles for each antigen; e.g., to test GATA and nt FY*265 with $F Y^{*} \mathrm{~A} / F Y^{*} B$ typing is obvious, while to test for other rare $F Y$ silencing nucleotide changes is not. The number of markers that can be assayed depends on such things as the ethnic population being tested, the reason for the testing, the number of probes that can be placed on one platform, and the cost. Another consideration is whether to use the results without confirmation by hemagglutination if it is unlikely to harm the patient. Furthermore, if we had a simple, inexpensive way to positively identify a donor at subsequent donations, should DNA typing of a donor be performed only once. Of value would be a fully automated system and positive sample identification from the beginning of the process (DNA preparation) to the end (result interpretation entered into data base). There are controversies in regard to who should be tested by PCR-based methods: as needed, donors and patients, newborns, or all people (table 3 ).

Hemagglutination is the gold standard technique to type RBCs for the presence or absence of blood group antigens. PCR-based assays, used as an adjunct to hemagglutination, will be a powerful tool that could radically change approaches used to support patients in their transfusion needs.

\section{Acknowledgment}

I thank Christine Lomas-Francis for critically review and Robert Ratner for help in preparation of this article.

\section{Disclosure}

The author received funding from BioArray Solutions for research studies.

\section{References}

1 Daniels G, van der Schoot CE, Olsson ML: Report of the Second International Workshop on Molecular Blood Group Genotyping. Vox Sang 2007;93:83-88.

2 Daniels G, Castilho L, Flegel WA, Fletcher A, Garratty $\mathrm{G}$, Levene C, Lomas-Francis C, Moulds JM, Moulds JJ, Olsson ML, Overbeeke M, Poole J, Reid ME, Rouger P, van der Schoot E, Scott M, Sistonen P, Smart E, Storry JR, Tani Y, Yu L-C, Wendel S, Westhoff C, Yahalom V, Zelinski T: International Society of Blood Transfusion Committee on Terminology for Red Cell Surface Antigens: Macao report. Vox Sang 2009;96:153-156.

3 Daniels G, Flegel WA, Fletcher A, Garratty G, Levene C, Lomas-Francis C, Moulds JM, Moulds JJ, Olsson ML, Overbeeke M, Poole J, Reid M, Rouger P, van der Schoot E, Sistonen P, Smart E, Storry J, Tani Y, Yu L-C, Wendel S, Westhoff C, Zelinski T: International Society of Blood Transfusion Committee on Terminology for Red Cell Surface Antigens: Cape Town report. Vox Sang 2007;92:250-253.

4 Lögdberg L, Reid ME, Lamont RE, Zelinski T: Human blood group genes 2004: chromosomal locations and cloning strategies. Transf Med Rev 2005;19: $45-57$.
5 Reid ME, Lomas-Francis C: Blood Group Antigen Facts Book, 2nd ed. San Diego, Academic Press, 2004.

6 Human Genome Variation Society: Blood Group Antigen Gene Mutation Database. $N C B I, d b R B C$ 2006; published on line www.ncbi.nlm.nih.gov/ projects/mhc/xslcgi.fcgi? cmd = bgmut/home

-7 Palacajornsuk P, Halter C, Isakova V, Tarnawski M, Farmar J, Reid ME, Chaudhuri A: Detection of blood group genes using multiplex SNaPshot method. Transfusion 2009:49:740-749.

8 Castilho L: The value of DNA analysis for antigens in the Duffy blood group system. Transfusion 2007;47(suppl):28S-31S

9 Westhoff CM: Rh complexities: serology and DNA genotyping. Transfusion 2007;47(suppl):17S-22S.

10 Storry JR, Reid ME, Fetics S, Huang C-H: Mutations in $G Y P B$ exon 5 drive the S-s- $\mathrm{U}^{\mathrm{var}}$ phenotype in persons of African descent: Implications for transfusion. Transfusion 2003;43:1738-1747.

11 Lomas-Francis C: The value of DNA analysis for antigens of the Kidd blood group system. Transfusion 2007;47(suppl):23S-27S.
12 van der Schoot CE, de HM, Engelfriet CP, Reesink HW, Panzer S, Jungbauer C, Schwartz DM, Mayr WR, Castilho L, St-Louis M, Long A, Denomme G, Semple E, Fernandes B, Flegel WA, Wagner F, Doescher A, Poli F, Villa MA, Paccapelo C, Karpasitou K, Veldhuisen B, Nogues N, Muniz-Diaz E, Daniels G, Martin P, Finning K, Reid ME: Genotyping for red blood cell polymorphisms. Vox Sang 2009;96:167-179.

13 Hillyer CD, Shaz BH, Winkler AM, Reid M: Integrating molecular technologies for red blood cell typing and compatibility testing into blood centers and transfusion services. Transf Med Rev 2008; 22:117-132.

14 Avent ND, Reid ME: The Rh blood group system: a review. Blood 2000;95:375-387.

15 Wagner FF., Frohmajer A, Flegel WA: RHD positive haplotypes in D negative Europeans. BMC Genet 2001;2:10.

16 Okuda H, Kawano M, Iwamoto S, Tanaka M, Seno T, Okubo Y, Kajii E: The RHD gene is highly detectable in RhD-negative Japanese donors. J Clin Invest 1997;100:373-379. 
17 Chang JG, Wang JC, Yang TY, Tsan KW, Shih MC, Peng CT, Tsai CH: Human $\mathrm{Rh}_{\text {Del }}$ is caused by a deletion of 1,013 bp between introns 8 and 9 including exon 9 of RHD gene. Blood 1998;92:2602-2604.

18 Singleton BK, Green CA, Avent ND, Martin PG, Smart E, Daka A, Narter-Olaga EG, Hawthorne LM, Daniels G: The presence of an RHD pseudogene containing a 37 base pair duplication and a nonsense mutation in Africans with the Rh D-negative blood group phenotype. Blood 2000;95:12-18

19 Denomme GA, Fernandes BJ: Fetal blood group genotyping. Transfusion 2007;47(suppl):64S-68S.

20 Lee S: The value of DNA analysis for antigens of the Kell and Kx blood group systems. Transfusion 2007; 47(suppl):32S-39S.

21 Denomme GA, Shahcheraghi A, Blackall DP, Oza KK, Garratty G: Inhibition of erythroid progenitor cell growth by anti-Ge3. Br J Haematol 2006; 133:443-444.

22 Reid ME, Oyen R, Storry J, Hue-Roye K, Rios $\mathrm{M}$ : Interpretation of RBC typing in multi-transfused patients can be unreliable. Transfusion 2000; 40(suppl):123S (abstract).

23 Wenk RE, Chiafari FA: DNA typing of recipient blood after massive transfusion. Transfusion 1997;37: 1108-1110.

-24 Legler TJ, Eber SW, Lakomek M, Lynen R, Maas JH, Pekrun A, Repas-Humpe M, Schroter W, Kohler M: Application of RHD and RHCE genotyping for correct blood group determination in chronically transfused patients. Transfusion 1999;39:852-855.

-25 Reid ME, Rios M, Powell VI, Charles-Pierre D, Malavade V: DNA from blood samples can be used to genotype patients who have recently received a transfusion. Transfusion 2000;40:48-53.
26 Rozman P, Dove T, Gassner C: Differentiation of autologous $A B O, R H D, R H C E, K E L, J K$, and $F Y$ blood group genotypes by analysis of peripheral blood samples of patients who have recently received multiple transfusions. Transfusion 2000; 40:936-942.

27 Reid ME, Yazdanbakhsh K: Molecular insights into blood groups and implications for blood transfusions. Curr Opin Hematol 1998;5:93-102.

28 Reid ME: Complexities of the Dombrock blood group system revealed. Transfusion 2005;45(suppl): 92S-99S.

29 Vichinsky EP, Luban NL, Wright E, Olivieri N, Driscoll C, Pegelow CH, Adams RJ: Prospective RBC phenotype matching in a stroke-prevention trial in sickle cell anemia: a multicenter transfusion trial. Transfusion 2001;41:1086-1092.

30 Adams RJ, McKie VC, Brambilla D, Carl E, Gallagher D, Nichols FT, Roach S, Abboud M, Berman B, Driscoll C, Files B, Hsu L, Hurlet A, Miller S, Olivieri N, Pegelow C, Scher C, Vichinsky E, Wang W, Woods G, Kutlar A, Wright E, Hagner S, Tighe F, Waclawiw MA: Stroke prevention trial in sickle cell anemia. Control Clin Trials 1998:19:110-129.

31 Westhoff CM: The structure and function of the Rh antigen complex. Semin Hematol 2007;44:42-50.

32 Storry JR, Olsson ML, Reid ME: Application of DNA analysis to the quality assurance of reagent red blood cells. Transfusion 2007;47(suppl):73S-78S.

33 Hashmi G, Shariff T, Seul M, Vissavajjhala P, Hue-Roye K, Charles-Pierre D, Lomas-Francis C, Chaudhuri A, Reid ME: A flexible array format for large-scale, rapid blood group DNA typing. Transfusion $2005 ; 45: 680-688$.
34 Hashmi G, Shariff T, Zhang Y, Cristobal J, Chau C, Seul M, Vissavajjhala P, Baldwin C, Hue-Roye K, Charles-Pierre D, Lomas-Francis C, Reid ME: Determination of 24 minor red blood cell antigens for more than 2000 blood donors by high-throughput DNA analysis. Transfusion 2007;47:736-747.

35 Reid ME, Rios M: Applications of molecular genotyping to immunohaematology. Br J Biomed Sci 1999; 56:145-152.

36 Reid ME: Applications of DNA-based assays in blood group antigen and antibody identification. Transfusion 2003;43:1748-1757.

37 Huang C-H, Liu PZ, Cheng JG: Molecular biology and genetics of the Rh blood group system. Semin Hematol 2000;37:150-165.

38 Lee S, Russo DCW, Reiner AP, Lee JH, Sy MY, Telen MJ, Judd WJ, Simon P, Rodrigues MJ, Chabert T, Poole J, Jovanovic-Srzentic S, Levene C, Yahalom V, Redman CM: Molecular defects underlying the Kell null phenotype. J Biol Chem 2001;276:2728127289.

39 Lucien N, Sidoux-Walter F, Olivès B, Moulds J, Le Pennec P-Y, Cartron J-P, Bailly P: Characterization of the gene encoding the human Kidd blood group/ urea transporter protein: evidence for splice site mutations in $\mathrm{Jk}_{\text {null }}$ individuals. J Biol Chem 1998; 273:12973-12980.

40 Furukawa K, Iwamura K, Uchikawa M, Sojka BN, Wiels J, Okajima T, Urano T, Furukawa K: Molecular basis for the p phenotype. Identification of distinct and multiple mutations in the alpha 1.4-galactosyltransferase gene in Swedish and Japanese individuals. J Biol Chem 2000;275:37752-37756.

41 Heaton DC, McLoughlin K: Jk(a-b-) red blood cells resist urea lysis. Transfusion 1982;22:70-71. 